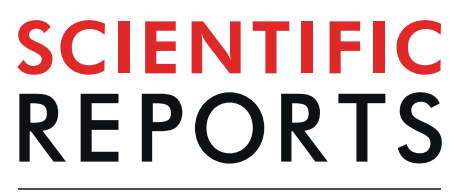

natureresearch

Check for updates

\title{
Neuroanatomy of the spinosaurid Irritator challengeri (Dinosauria: Theropoda) indicates potential adaptations for piscivory
}

\begin{abstract}
Marco Schade ${ }^{1,2 \bowtie}$, Oliver W. M. Rauhut ${ }^{2,3,4}$ \& Serjoscha W. Evers ${ }^{5}$
Spinosauridae, a theropod group characterized by elongated snouts, conical teeth, enlarged forelimbs, and often elongated neural spines, show evidence for semiaquatic adaptations and piscivory. It is currently debated if these animals represent terrestrial carnivores with adaptations for a piscivorous diet, or if they largely lived and foraged in aquatic habitats. The holotype of Irritator challengeri, a nearly complete skull from the late Early Cretaceous Santana Formation of northeastern Brazil, includes one of the few preserved spinosaurid braincases and can provide insights into neuroanatomical structures that might be expected to reflect ecological affinities. We generated digital models of the neuroanatomical cavities within the braincase, using computer tomography (CT) data. The cranial endocast of Irritator is generally similar to that of other non-maniraptoriform theropods, with weakly developed distinctions of hindbrain and midbrain features, relatively pronounced cranial flexures and relatively long olfactory tracts. The endosseous labyrinth has a long anterior semicircular canal, a posteriorly inclined common crus and a very large floccular recess fills the area between the semicircular canals. These features indicate that Irritator had the ability for fast and well-controlled pitch-down head movements. The skull table and lateral semicircular canal plane are strongly angled to one another, suggesting a downward angling of approximately $45^{\circ}$ of the snout, which reduces interference of the snout with the field of vision of Irritator. These neuroanatomical features are consistent with fast, downward snatching movements in the act of predation, such as are needed for piscivory.
\end{abstract}

Spinosauridae is a large-bodied theropod group within Megalosauroidea known from the Cretaceous, although their phylogenetic relationships indicate that the clade must have originated in the Jurassic ${ }^{1}$. Spinosaurids are characterized by a long and slender skull, conical teeth, strongly developed forelimbs with exceptionally large thumb claws and elongated neural spines ${ }^{2-6}$. Due to superficial similarities in cranial form with piscivorous Crocodilia, such as the gharial, and the wealth of fossil fish within the assemblages they were found in, spinosaurids were repeatedly associated with a semiaquatic lifestyle and piscivory [e.g. ${ }^{3,7-12}$ ]. Direct evidence for piscivory comes from acid-etched fish scales in the stomach contents of Baryonyx walkeri ${ }^{3}$, although the same individual also includes terrestrial dinosaur bones of a juvenile ornithopod. Predation on pterosaurs has also been shown for spinosaurids ${ }^{13}$. Thus, direct evidence for spinosaurid diets indicates a mix, or opportunistic behaviour with a tendency towards relatively small prey items. Additional evidence to support semiaquatic adaptations beyond dietary preference in spinosaurids comes from: isotope signals acquired from tooth enamel of samples from different geographical contexts, which show that spinosaurids spent a significant amount of their lifetime in water ${ }^{8,14,15}$; the suspected elevated position of the orbits in the skull ${ }^{12}$; the occurrence of pachyostosis in the femur of a specimen referred to Spinosaurus aegyptiacus ${ }^{10}$; though see ${ }^{16}$ for taxonomic identification]; and the presence of a fluke-like tail that was probably used for aquatic, tail-propelled locomotion in the same specimen of $S$. aegyptiacus ${ }^{17}$.

${ }^{1}$ Institute of Geography and Geology, Palaeontology and Historical Geology, University of Greifswald, 17489, Greifswald, Germany. ${ }^{2}$ Department of Earth and Environmental Sciences, Palaeontology and Geobiology, LudwigMaximilians-Universität, 80333, München, Germany. ${ }^{3}$ Bayerische Staatssammlung für Paläntologie und Geologie, Staatliche Naturwissenschaftliche Sammlungen Bayerns (SNSB), 80333, München, Germany. ${ }^{4}$ GeoBioCenter, Ludwig-Maximilians-Universität, 80333, München, Germany. ${ }^{5}$ Department of Geosciences, University of Fribourg,

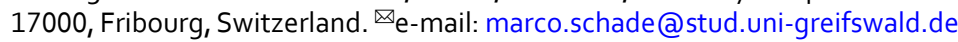


a

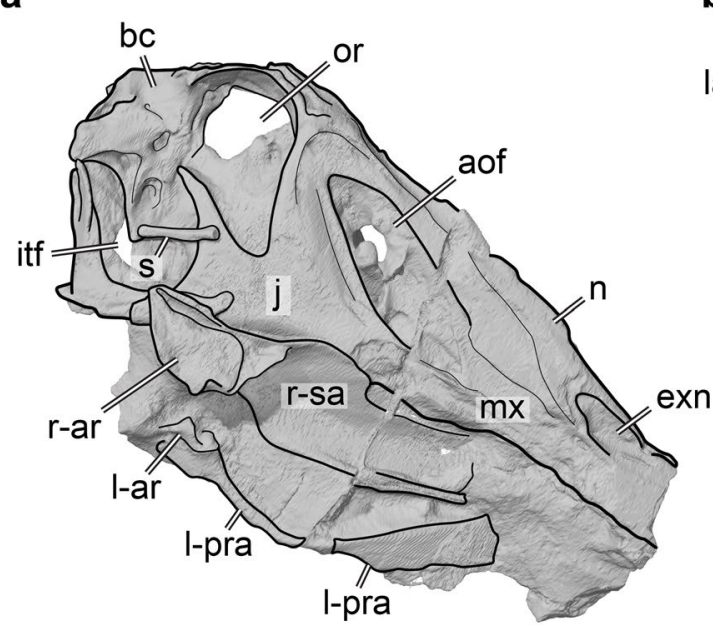

b

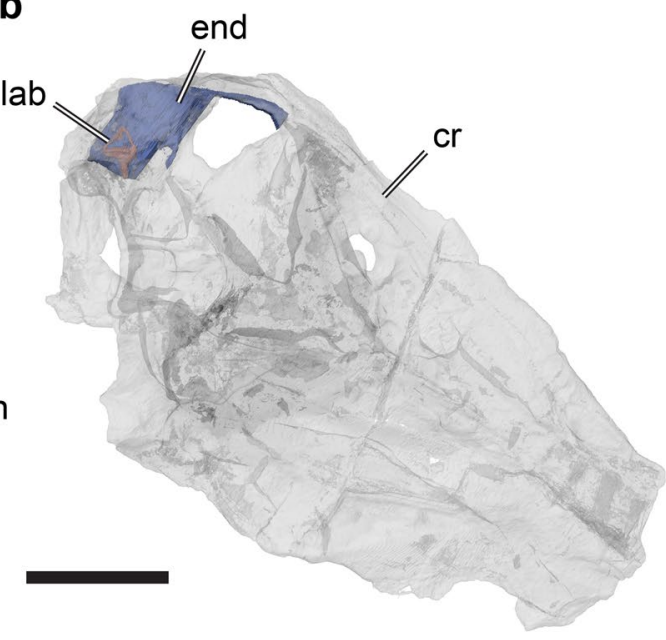

Figure 1. 3D renderings of the holotype fossil of Irritator challengeri (SMNS 58022) in right lateral view. (a) solid rendering of the skull with interpretative line drawing indicating gross anatomy; (b) transparent rendering of the skull with solid rendering of the cranial endocast and endosseous labyrinth. Note that the skull is inclined according to the 'alert' head pos-ture inferred by lateral semicircular canal horizontality (see text for details). Scale bar equals $100 \mathrm{~mm}$. Abbreviations: aof, antorbital fenestra; ar, articular; bc, brain-case; cr, cranium; end, cranial endocast; exn, external naris; itf, infratemporal fenestra; $j$, jugal; 1-, indicates left element; lab, endosseous labyrinth; mx, maxilla; $n$, nasal; or, orbit; pra, prearticular; r-, indicates right element; s, stapes; sa, surangular.

Spinosaurid material beyond isolated teeth is rare, making partial skeletons and especially skull remains particularly valuable to test for the presence of ecological adaptations. So far, the only spinosaurid taxon for which an almost complete skull is known is Irritator challengeri (SMNS 58022; Staatliches Museum für Naturkunde Stuttgart, Stuttgart, Germany) from the Aptian-Albian Santana Formation of Brazil ${ }^{18,19}$ (Fig. 1). Modern methodological advances, such as computer tomography (CT) scanning methods, can reveal new details of specimens, which in turn give insights into unknown aspects of spinosaurid functional anatomy, ecology and evolution.

The braincase of vertebrates houses the brain and is closely associated with essential sensory organs [see for theropods e.g. $\left.{ }^{20-26}\right]$. In addition, the braincase provides muscle attachment sites for the jaw and neck muscles, and directly articulates via the first neck vertebra with the postcranial skeleton. Equipped with bony crests as display devices, braincases can even be important for assessing behavioral questions ${ }^{24}$.

In this study, we use CT scanning of the well-preserved braincase of Irritator challengeri to reveal its neuroanatomy. I. challengeri may represent the apex predator of the Santana Formation, which is one of the most important Early Cretaceous (Aptian-Albian) fossil lagerstätten from South America. The outer morphology of its braincase will be described elsewhere. The digital reconstructions of the endocast and inner ear give new insights into neuroanatomical features and associated sensory organs of this animal, and enable ecological implications to be hypothesized.

\section{Results}

Cranial endocast and innervation. The cranial endocast of SMNS 58022 is generally similar to that of other non-maniraptoriform theropods, in that many features of the hindbrain and midbrain (e.g. cerebellum and optic lobes) are not confidently perceivable as distinct structures on the surface of the endocast (Fig. 2). This indicates a poor direct correspondence between neural tissues and endocranial cavity surface, as in many other reptiles including crocodiles, lepidosaurs, and turtles [e.g. ${ }^{27-30}$ ]. A much closer brain-braincase correspondence is realized in strongly encephalised groups, which include some coelurosaurs, avian theropods, pterosaurs, or mammaliforms [e.g. ${ }^{31-37}$ ]. The endocast of SMNS 58022 is less tubular than that of crocodiles or many non-avialan coelurosaurs [e.g. $\left.{ }^{24,29}\right]$. Instead, pontine and cephalic flexures are more pronounced, resulting in a midbrain section of the endocast that is relatively strongly angled between the hindbrain and forebrain (Fig. 2a). This is consistent with observations for basal tetanurans and ceratosaurs [e.g. ${ }^{20,23,25,38,39}$. Near the cephalic flexure, the endocast of SMNS 58022 shows a weakly developed dural peak (Fig. 2a). However, because of a damage on the parietal, an accurate reconstruction of the area in which the pineal gland would be expected cannot be provided. As in other basal tetanurans and ceratosaurs $\left[\right.$ e.g..$^{20,23}$, but unlike coelurosaurs ${ }^{24}$, the dorsal middle cerebral vein exits the cranial endocast well below the level of the dural peak (Fig. 2a,b) in SMNS 58022.

In the forebrain, the cerebral hemispheres are distinguishable as laterally expanded but weakly delimited bulbs on the dorsolateral surface of the endocast of SMNS 58022 (Fig. 2). The impressions of the olfactory tracts are preserved along the ventral surface of the frontals. The conjoined impressions of the olfactory tracts and bulbs are around $55 \mathrm{~mm}$ in length. Anteriorly, the olfactory tract gets wider and diverges into distinct olfactory bulbs, which are dorsally separated by a shallow sulcus (Fig. 2b,d). Long olfactory tracts are considered plesiomorphic within theropods ${ }^{24}$, and are shortened in theropods closer to the avian crown than basal tetanurans ${ }^{24}$. The full extent of the olfactory bulbs could not be reconstructed for SMNS 58022, due to insufficient preservation 
a

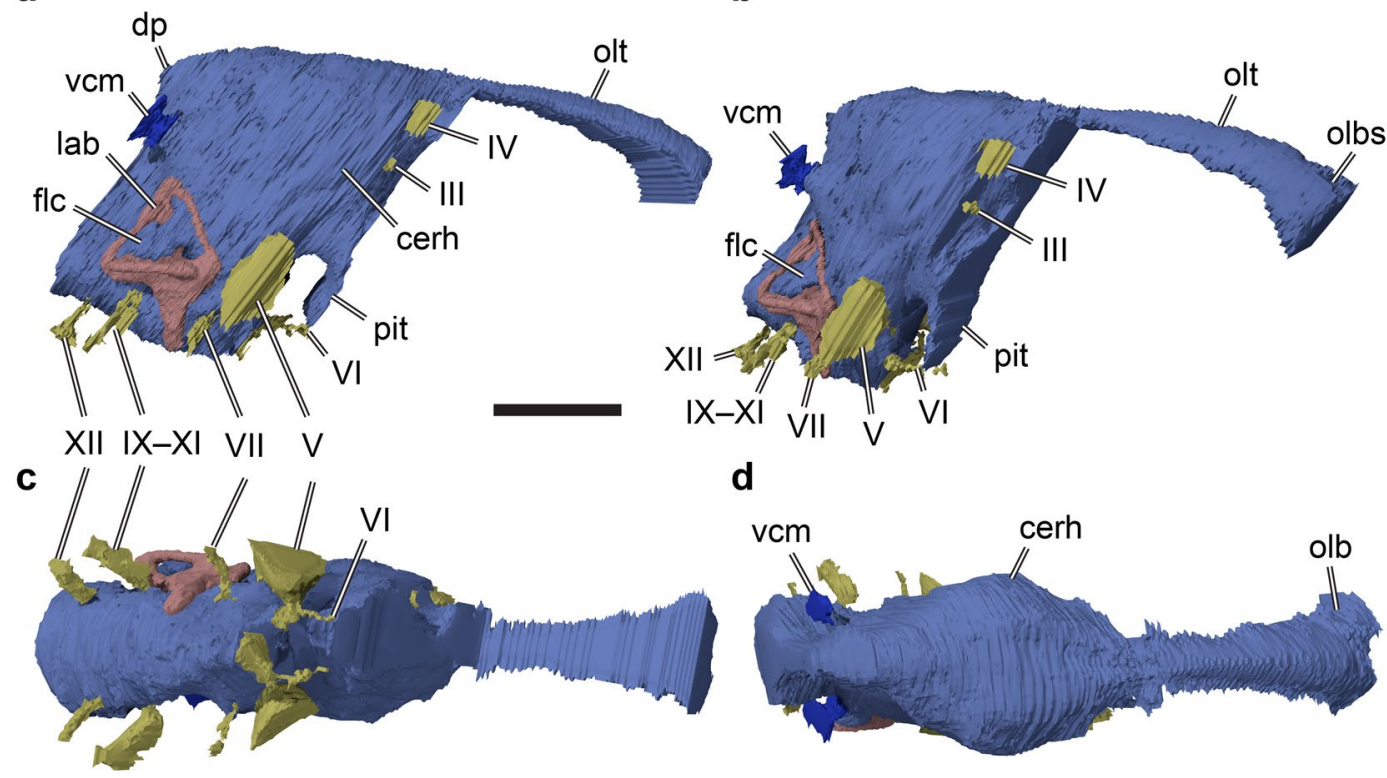

Figure 2. 3D rendering of the cranial endocast, cranial nerves, endosseous labyrinth, and as-sociated structures of the holotype fossil of Irritator challengeri (SMNS 58022). (a) right lat-eral view; (b) oblique view, roughly anterolaterally oriented; (c) ventral view; (d) dorsal view. Scale bar equals $30 \mathrm{~mm}$. Abbreviations: cerh, cerebral hemisphere; dp, dural peak; flc, floc-cular recess; III, oculomotor nerve; IV, trochlear nerve; IX-XI, endocast of the metotic fissure, holding the glossopharyngeal (IX), vagus (X), and accessory (XI) nerves; lab, endosseous lab-yrinth; olb, olfactory bulb; olbs, olfactory bulb sulcus; olt, olfactory tract; pit, pituitary; $\mathrm{V}$, trigeminal nerve; VI, abducens nerve; VII, facial nerve; vcm, dorsal middle cerebral vein; XII, hypoglossal nerve.

anteriorly. Ventral to the base of the olfactory tracts, the orbitosphenoid captures the courses of the cranial nerves III (oculomotor nerve) and IV (trochlear nerve) (Fig. 2a,b). Anteroventrally in the forebrain, the impression of the pituitary fossa is clearly visible in SMNS 58022 (Fig. 2a,b). Although no clear cerebral carotid canal could be identified, the paired abducens nerve (CN VI) canals could be reconstructed (Fig. 2a-c). The position of the foramen for the trigeminal nerve $(\mathrm{CN} \mathrm{V})$ is posterodorsal to the abducens canal. The respective foramen is large and clearly visible externally ${ }^{19}$. The facial nerve (CN VII) originates anteriorly to the position of the cochlear duct, whereas the metotic foramen and recessus scalae tympani for CN IX-XI is found posterior to the cochlear duct (Fig. 2a-c). Hypoglossal nerve (CN XII) canals were identified on both sides, whereas Sues et al. ${ }^{19}$ were only able to locate one such foramen externally, on the left side of the specimen.

In the midbrain region, somewhat posteroventrally to the cerebral expansion, the endocast shows a posteroventrally directed flap that projects off the cerebellum, the floccular lobe (flocculus in the following; Figs. 2a,b, $3 \mathrm{a}-\mathrm{d})$. The flocculus of SMNS 58022 is very large; it projects posteriorly into the space confined by the posterior semicircular canal and secondary common crus of the endosseous labyrinth, and extends laterally to the level of the lateral semicircular canal. Thus, the flocculus of Irritator challengeri is much larger than that of other basal tetanurans [e.g. ${ }^{20,22,25}$ ], and even most coelurosaurs [e.g. ${ }^{40}$, but is similar in size to taxa that reportedly have large flocculi (e.g. Conchoraptor gracilis ${ }^{26}$ ).

The medulla oblongata in the hindbrain is relatively broad mediolaterally, and connected with the foramen magnum.

The volume of the endocranial cavity was measured to be approximately $80 \mathrm{~cm}^{3}$ (measured as suggested in ${ }^{23}$ ).

Endosseous labyrinth. The endosseous labyrinth of SMNS 58022 is composed of the dorsally positioned vestibular system that includes the semicircular canals, and a ventrally tapering cochlear duct (Fig. 3). The cochlear duct is relatively long and dorsoventrally as tall as the semicircular canal system (Fig. 3a,e). It is gently ventromedially inclined (Fig. 3c,d,g,h). The vertical semicircular canals are strongly asymmetrical: the common crus is posteriorly directed rather than strictly dorsally (Fig. 3e). As a consequence, the posterior semicircular canal forms a low and relatively short arc, whereas the anterior semicircular canal is long and posterodorsally forms a $180^{\circ}$ turn to reach the common crus. The course of the posterior semicircular canal does not lie in a single vertical plane, but the midpart of the canal is slightly bowed anterolaterally. In many tetrapods, the posterior portion of the lateral semicircular canal and the ventral portion of the posterior semicircular canal intersect, and form a singular cavity, the secondary common crus ${ }^{30}$. In SMNS 58022, the posterior and lateral semicircular canal also intersect, but the courses of the individual paths of the membranous ducts within the intersection are still clearly visible in the endosseous labyrinth model as impressions within the secondary common crus. Although these impressions are difficult to see in standard orientation figures of the endosseous labyrinth model (Fig. 3d,h), they are clearly visible in the actual $3 \mathrm{D}$ model $\left(\mathrm{see}^{41}\right)$. The posterior semicircular canal arcs ventrally underneath the lateral semicircular canal, which curves medial to the posterior canal toward the common crus. The imprints of 
a

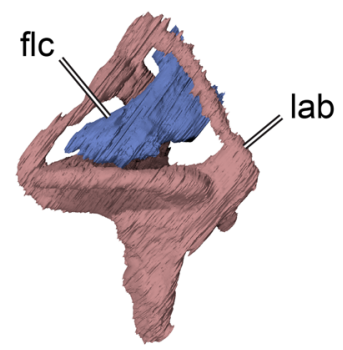

e

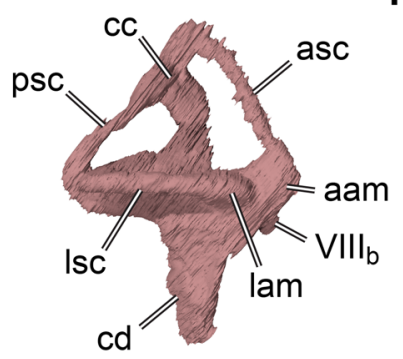

b

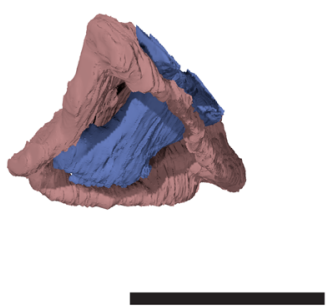

f

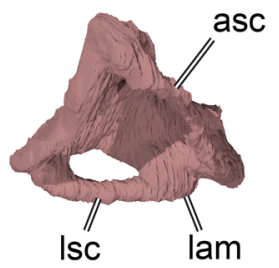

C

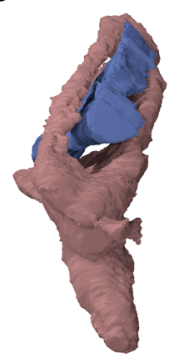

g

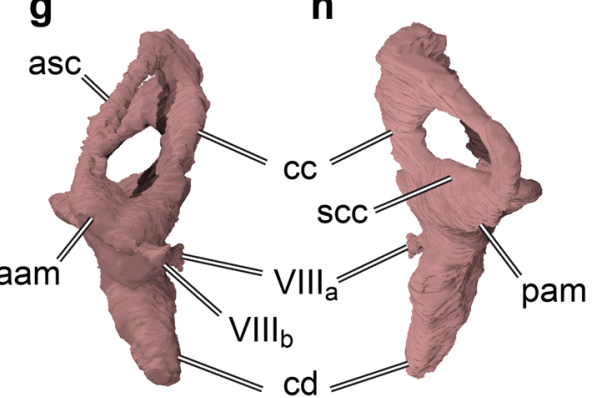

d

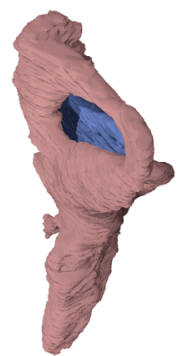

h

Figure 3. 3D rendering of right endosseous labyrinth and floccular recess of the holotype fossil of Irritator challengeri (SMNS 58022). (a)-(d), 3D renderings including the floccular re-cess; (e)-(f), excluding floccular recess. (a), (e), lateral view; (b), (f), dorsal view; (c), (g), anterior view; (d), (h), posterior view. Scale bar equals $20 \mathrm{~mm}$. Abbreviations: aam, anterior ampulla; asc, anterior semicircular canal; cc, common crus; cd, cochlear duct; flc, floccular recess; lab, en-dosseous labyrinth; lam, lateral ampulla; lsc, lateral semicircular canal; pam, posterior am-pulla; psc, posterior semicircular canal; scc, secondary common crus; VIIIa, medial branch of vestibulocochlear nerve; VIIIb, anterior branch of vestibulocochlear nerve.

the posterior LSC and ventral PSC portions provide evidence that the semicircular ducts were relatively widely separated in life, as is the case in many modern birds, in which a secondary common crus is largely absent ${ }^{42}$.

Pneumatic cavities. Pneumatic cavities in the braincase of SMNS 58022 are present, but hard to delimitate within our CT data. This is in part because some pneumatic cavities, particularly the caudal tympanic recess within the paroccipital process, and a recess directly ventral to the brain within the basioccipital, tentatively identified as the medial subcondylar recess [see ${ }^{24,43}$ for theropod braincase pneumaticity], are interrupted by extensive webbing of laminae. Seemingly, there are more pneumatic recesses present within the braincase of SMNS 58022, including minor cavities within the basioccipital and the prootic, as well as a basisphenoid recess and a subsellar recess within the basisphenoid. In very general terms, the extent of braincase pneumaticity seems to be higher than in ceratosaurs ${ }^{23,44}$, but less than in tyrannosaurs ${ }^{24}$.

\section{Discussion}

Auditory capabilities. Auditory capability and cochlear duct length have been hypothesized to be correlated among extant archosaurs ${ }^{45}$. We used the equations derived by Walsh et al. ${ }^{45}$ alongside digital measurements (cochlear duct length $=18.1 \mathrm{~mm}$; basicranium length $=75.3 \mathrm{~mm}$ ) to infer the mean hearing frequency $(1950 \mathrm{~Hz})$ and frequency band width $(3196 \mathrm{~Hz})$ for Irritator challengeri. We only consider these values as rough guidance, but the resulting frequency range between c. $350-3550 \mathrm{~Hz}$ places I. challengeri around the lower end of the sensitivity range inferred for modern birds, but above that for crocodiles ${ }^{45}$. Furthermore, the estimates are in approximate agreement with those calculated for other theropod dinosaurs [e.g. ${ }^{40}$. Additional cues for the auditory capabilities can possibly be inferred from pneumaticity. Increased volume achieved by extensive tympanic pneumaticity, as observed in extant Aves and Crocodilia, but also tyrannosaurs and many maniraptoran theropods ${ }^{46}$, is thought to impact impedance matching of the middle ear by reducing the acoustic stiffness and improving stapes vibration. These effects facilitate the reception of low frequencies, as well as the amplification of frequency-depending sound $\mathrm{s}^{24,29,47}$. The lesser degree of tympanic pneumatization of SMNS 58022, which probably represents a symplesiomorphy shared with other basal tetanurans, might indicate that the middle ear of I. challengeri was less specialized than those of tyrannosaurs. It is noteworthy that the stapes of SMNS 58022 is relatively more robust than in some other basal tetanurans, such as Allosaurus spp. ${ }^{48,49}$, which might negatively affect the efficiency of the acoustic transformer ratio, and thus of impedance matching, of I. challengeri.

Vestibular anatomy as a guide to ecological reconstructions?. It is currently unclear how informative labyrinth geometry is for inferring habitat ecology in reptiles. The semicircular canals, which are the focus of most studies that test for such correlations, are used in gaze stabilization by detecting angular accelerations of the head as inputs to the vestibulo-ocular (VOR) and vestibulo-collic (VCR) reflexes ${ }^{50}$. Endolymphatic flow within the inner ear organ is determined by semicircular canal geometry, and the shape of the vestibular organ is therefore expected to vary depending on locomotor mode, as has been found for many mammal groups [e.g. ${ }^{51-54}$. 
Functional changes in vestibular anatomy are expected to be largest in groups that experienced strong ecological transitions, such as the evolution of secondarily marine lifestyles or flight. However, for both these transitions, no characteristic shape change uniquely linked to either ecological adaptation has yet been found. In birds, studies that test for ecological signals in the vestibular anatomy so far fail to find correlations with flight ability or style. For instance, the size of the floccular lobe does not indicate flight ability ${ }^{35}$. Benson et al..$^{42}$ found little locomotor signal within the semicircular canal system size or semicircular canal shape of birds. They suggest that other constraints, such as visual acuity, head size, and spatial constraints within the cranium could instead determine the major variation associated with labyrinth shape $\mathrm{e}^{42}$. Some studies have reported potential aquatic adaptations to the endosseous labyrinth in non-dinosaurian reptiles ${ }^{30,55-57}$. However, the hypothesis that aquatic tetrapods have low aspect ratios (i.e. comparatively dorsoventrally low and anteroposteriorly long labyrinth $\mathrm{s}^{55}$;) is not supported by more recently collected data ${ }^{30}$. Additionally, thick endosseous semicircular canals, although found in several secondarily marine groups ${ }^{30,56,57}$, can also be present in highly terrestrial animals ${ }^{30}$. Furthermore, the endosseous labyrinths of phylogenetically shallow marine lineages, such as penguins or seals seem to be influenced more strongly by other factors like phylogeny (penguins: ${ }^{.5,56}$; neodiapsids: ${ }^{58}$ ), or neck agility $\left(\right.$ seals: ${ }^{59}$ ), rather than habitat ecology.

Despite the above-mentioned reservations against clear ecological signals in the vestibular anatomy of reptiles, potential functional adaptations of the dinosaurian labyrinth have been reported throughout the literature. For instance, changes in labyrinth geometry associated with the evolution of bipedality within dinosaurs, particularly the elongation of the vertical semicircular canals, have been recorded for dinosaurs ${ }^{60}$. On the other hand, these changes could not be found in an ontogenetic labyrinth series of the dinosaur Massospondylus carinatus ${ }^{61}$, which experiences a change from quadrupedality to bipedality during ontogeny ${ }^{62}$.

Spinosaurids are deeply nested within the Theropoda, a clade of obligate bipedal, comparatively agile, and terrestrial animals. Even if spinosaurids had a semiaquatic ecology [e.g. ${ }^{10}$ ], it is quite possible that ancestral constraints on the theropodan bauplan dominate the shape of the spinosaurid labyrinth [e.g. ${ }^{58}$ ]. Therefore, semiaquatic adaptations are not necessarily expected to be overly obvious, or present at all, and their absence cannot be taken as strong evidence against semiaquatic lifestyles. In the following, we discuss and interpret three aspects of the neuroanatomy of Irritator challengeri that have been the focus of many studies that try to synthesize ecological adaptations from neuroanatomical structures: the size of the floccular recess, the size of the anterior semicircular canal, and the relative orientation of the lateral semicircular canal.

Behavioral interpretations of neuroanatomy. SMNS 58022 shows enlarged floccular recesses. The flocculus is important in the control and coordination of head, eye, and neck movements during gaze stabilization, by being involved in processing the vestibulo-ocular (VOR) and vestibulo-collic (VCR) reflexes ${ }^{33,35,51}$. Additionally, the flocculus plays a role in the reflex control of neck movements ${ }^{63}$. Although the floccular recess may also house non-neural tissues ${ }^{35}$, floccular size has been interpreted to be grossly indicative of the amount of neural tissue and, by inference, the amount of respective signal procession ${ }^{33}$. A small flocculus endocast is conversely not necessarily indicative of a small amount of respective neural tissue, because the floccular lobe also extends within the cerebellum of extant birds ${ }^{29,35}$. However, a reduction in floccular size in the abelisaurid certosaurian Majungasaurus crenatissimus has been interpreted to indicate a decreased reliance on quick movement and sophisticated gaze-stabilization mechanisms in this taxon ${ }^{23}$, though not necessarily in other abelisaurids $s^{44,64}$. In pterosaurs, enlarged floccular recesses have been interpreted as an adaptation to eye-guided pursuit hunting of fish, albeit aerially ${ }^{33}$. Within non-avian theropod dinosaurs, large floccular recesses are common among coelurosaurs, but this structure seems relatively smaller in basal tetanurans [e.g. ${ }^{20,26,40,44}$. Among birds, flocculus sizes vary. It is noteworthy that particularly large flocculus sizes have been noted for many waterbirds (Procellariiformes, i.e. albatrosses and kin; Phaethoniformes, i.e. tropicbirds; Charadriiformes, i.e. gulls and kind; Anseriformes, i.e. ducks, geese, and swans; Gaviiformes, i.e. loons) and birds with particularly long necks (Rheiformes, i.e. Rhea; Ciconiiformes, i.e. storks) ${ }^{35,64}$. However, Falconiformes (falcons) and some Passeriformes (perching birds) also have large floccular sizes ${ }^{35}$. Although interpretations of floccular sizes are not straightforward [e.g. ${ }^{35}$ ], we interpret the large floccular size of Irritator challengeri as indicative for the relative importance of VOR and VCR coordination, particularly because large floccular sizes are unusual for the inferred phylogenetic position of spinosaurids.

Additional possible behavioural clues come from the semicircular canal system, particularly the anterior and lateral semicircular canals. In Irritator challengeri, the anterior semicircular canal is particularly long, with its length being furthermore increased by the posterodorsally inclined common crus. As the anterior semicircular canal is more sensitive to pitch-down movements of the head than the other semicircular canals ${ }^{65,66}$, we suggest that this kind of sensitivity was particularly important for I. challengeri. Research suggests that 'alert' head orientation can be inferred for animals by aligning the plane of the lateral semicircular canal with a horizontal plane paralleling the ground ${ }^{33,50,66-68}$. Arranging the lateral semicircular canal in SMNS 58022 horizontally, its skull is inclined downwards at approximately $45^{\circ}$ (Fig. 1b). This represents a rather strong ventral orientation of the snout tip, and could be interpreted to maximize the field of binocular vision by avoiding obstruction by the elongated snout [see also ${ }^{24}$ ]. This approach of inferring head posture has been criticized ${ }^{69}$ based on data that show that modern birds have a range of realized orientation values of the lateral semicircular canal that deviate from horizontality by up to c. $20^{\circ}$ to either side of the horizontal plane ${ }^{67}$. However, the same data show that birds with long beaks, such as storks, tend to have labyrinths that are pitched downward with their lateral semicircular canal planes ${ }^{67,69}$, which would even increase the downward inclination inferred for I. challengeri. Even extremely upward pitched labyrinth orientations of $20^{\circ}$ would result in a strong ventral inclination of the head of $I$. challengeri by approximately $25^{\circ}$. Furthermore, strong downward orientation of the snout of $I$. challengeri is independently supported by the slightly posteroventrally rotated occipital condyle. Therefore, we think that a strong 
downward orientation of approximately $45^{\circ}$ is supported for I. challengeri despite the caution that is warranted when making inferences about head orientation ${ }^{69}$.

The above features - particularly a good eye-head coordination, sensitivity for pitch-down movements, and a ventrally inclined snout facilitating three-dimensional vision - are features that are presumably important for pursuit hunters, particularly for animals that hunt prey that is small and agile in comparison to their own body size. These findings are consistent with data from skull mechanics and functional anatomy in spinosaurids $s^{7,70}$. Although the known direct evidence for predation in spinosaurids ${ }^{3,13}$ indicates an opportunistic feeding behaviour, fish might have played an important role in the diet of these animals. The 'alert' head posture of Irritator challengeri, in which the snout is held downward, furthermore possibly allowed the animal to tuck its snout into the water, while the retracted nares and eyes were not submerged. Possible mechanoreceptor foramina similar to those of crocodiles ${ }^{71}$ have been identified for spinosaurids ${ }^{10}$, although such structures can also be found in clearly terrestrial theropods $\mathrm{s}^{72}$. The enlarged anterior semicircular canal facilitated fast downward movements, which were coordinated in part by a large floccular recess, and in conjunction allowed snapping movements during hunting of small prey. This functional hypothesis requires fast neck movements. Thus, independent skeletal evidence in support of our interpretation might come from the morphology of the cervical vertebrae of spinosaurids. Although this part of the skeleton is not preserved in I. challengeri, certain features of spinosaurid cervical morphology are consistently present among different members of the group, justifying the use of comparative evidence ${ }^{1,16}$. Spinosaurids have comparatively long anterior and mid-cervical centra ${ }^{16}$, which make their necks considerably longer than those of other large-bodied theropods. Strong ventral rugosities on the mid-cervical to posterior centra of the spinosaurid Sigilmassasaurus brevicollis have been interpreted as osteological correlates for strong dorsoventral flexion musculature ${ }^{16}$. All of this evidence indicates a specialization of these gigantic predators on considerably smaller and elusive prey, including fish, which is remarkably different from that of other large-sized theropods, such as tyrannosaurids or carcharodontodsaurids [e.g. ${ }^{73-75}$ ], providing further evidence for niche partitioning between coeval spinosaurid and non-spinosaurid theropod taxa.

\section{Conclusions}

Irritator challengeri, the first spinosaurid for which neuroantomical features are documented, has a cranial endocast that shows features consistent with the inferred phylogenetic position of spinosaurids as basal tetanurans. These include weakly demarcated brain regions, elongate olfactory tracts and pronounced cranial flexures. $I$. challengeri has an enlarged floccular recess, which is an unusual feature for basal tetanurans. The vestibular part of the endosseous labyrinth is characterized by a large anterior semicircular canal. A large flocculus and anterior semicircular canal indicate that $I$. challengeri could move its head downwards in a fast and coordinated fashion. The lateral semicircular canal orientation suggests a downward inclined snout posture, which enables unobstructed, stereoscopic forward vision, important for distance perception and thus precise snatching movements of the snout. The suite of neuroanatomically facilitated behavioural capabilities inferred for I. challangeri are those expected for animals that mostly hunt small and agile prey. Although these prey items could be small terrestrial animals, our interpretations are consistent with, and corroborate independent evidence for the hypothesis for an at least partially piscivorous diet of spinosaurids.

\section{Materials and Methods}

The holotype and only known specimen of Irritator challengeri (SMNS 58022) is an almost complete skull (Fig. 1). It is about $55 \mathrm{~cm}$ long and well preserved, lacking only the premaxillae and a few other skull bones, especially of the splanchocranium. The specimen has suffered from slight transverse compression and disarticulation of the posterolateral parts of the skull roof, although some of the disarticulated elements are preserved in displaced positions within the skull, such as the postorbital ${ }^{19}$.

We scanned SMNS 58022 originally with a medical Siemens Somatom Force CT scanner (dual source) (voltage: $120 \mathrm{kV}$, X-ray tube current: $1365 \mu \mathrm{A}$, exposure time: $154 \mathrm{~ms}$, voxel size: $0.703123 \mathrm{~mm} \times 0.703124 \mathrm{~mm}$ $\times 3 \mathrm{~mm}$ ) in the German Heart Centre in Munich. This scan was the base for all digital reconstructions shown herein, except the inner ear and flocculus, which were visible but poorly resolved in the original scan. In order to get higher resolution data for the labyrinth reconstruction, we conducted a second scan focused only on the braincase, using a Zeiss Metrotom 1500 (voltage: $180 \mathrm{kV}$, X-ray tube current: $1800 \mu \mathrm{A}$, exposure time: $250 \mathrm{~ms}$, voxel size: $0.09713 \mathrm{~mm}$ ) in a subsidiary of Zeiss in Essingen. Digital segmentation and measurements were produced with Amira (5.6.). We used manual segmentation to create our models. Although the density contrast between the cranium and sediment infill of internal spaces was relatively weak, the boundary between bone surface and sediment infill is clearly visible in the slice data. 3D models of the high-resolution flocculus and endosseous labyrinth were aligned with the respective low-resolution structures in Blender $2.79 \mathrm{~b}$ to get composite figures of models from both scans. A composite neuroanatomical model, as well as individual 3D models and the two CT scans are deposited online ${ }^{41}$.

\section{Data availability}

The CT slice data and 3D files of SMNS 58022, are published online ${ }^{41}$, in the repository MorphoSource, Project P 951: https://www.morphosource.org/Detail/ProjectDetail/Show/project_id/951.

Received: 26 February 2020; Accepted: 18 May 2020;

Published online: 09 June 2020 


\section{References}

1. Carrano, M. T., Benson, R. B. J. \& Sampson, S. D. The phylogeny of Tetanurae (Dinosauria: Theropoda). J. Syst. Palaeontol. 10, 211-300, https://doi.org/10.1080/14772019.2011.630927 (2012).

2. Stromer, E. Ergebnisse der Forschungsreisen Prof. Stromers in den Wüsten Ägyptens. II Wirbeltier-Reste der Baharije-Stufe (unterstes Cenoman). 3. Das Original des Theropoden Spinosaurus aegyptiacus nov. gen., nov. spec. Abh. Math.-Phys. Kl, K. Bayer. Akad. Wiss. 28, 1-32 (1915).

3. Charig, A. J. \& Milner, A. C. Baryonyx walkeri, a fish-eating dinosaur from the Wealden of Surrey. J. Syst. Palaeontol. 53, 11-70 (1997).

4. Sereno, P. C. et al. A long-snouted predatory dinosaur from Africa and the evolution of spinosaurids. Science 282, 1298-1302 (1998).

5. Sasso, C. D., Maganuco, S., Buffetaut, E. \& Mendez, M. A. New information on the skull of the enigmatic theropod Spinosaurus, with remarks on its size and affinities. J. Vertebr. Paleontol. 25, 888-896; https://doi.org/10.1671/0272-4634(2005)025[0888:NIOTSO]2.0 .CO;2 (2005).

6. Allain, R., Xaisanavong, T., Richir, P. \& Khentavong, B. The first definitive Asian spinosaurid (Dinosauria: Theropoda) from the Early Cretaceous of Laos. Sci. Nat. 99, 369-377, https://doi.org/10.1007/s00114-012-0911-7 (2012).

7. Rayfield, E. J., Milner, A. C., Xuan, V. B. \& Young, P. G. Functional morphology of spinosaur 'crocodile-mimic' dinosaurs. J. Vertebr. Paleontol. 27, 892-901; https://doi.org/10.1671/0272-4634(2007)27[892:FMOSCD]2.0.CO;2 (2007).

8. Amiot, R. et al. Oxygen isotope evidence for semi-aquatic habits among spinosaurid theropods. Geology 38, 139-142, https://doi. org/10.1130/G30402.1 (2010)

9. Läng, E. et al. Unbalanced food web in a Late Cretaceous dinosaur assemblage. Palaeogeogr. Palaeoclimatol. Palaeoecol. 381-382, 26-32, https://doi.org/10.1016/j.palaeo.2013.04.011 (2013).

10. Ibrahim, N. et al. Semiaquatic adaptations in a giant predatory dinosaur. Science 345, 1613-1616, https://doi.org/10.1126/ science.1258750 (2014)

11. Hone, D. W. E. \& Holtz, T. R. Jr. A century of spinosaurs - a review and revision of the Spinosauridae with comments on their ecology. Acta Geol. Sin-Engl. 91, 1120-1132, https://doi.org/10.1111/1755-6724.13328 (2017).

12. Arden, T. M. S., Klein, C. G., Zouhri, S. \& Longrich, N. R. Aquatic adaptation in the skull of carnivorous dinosaurs (Theropoda: Spinosauridae) and the evolution of aquatic habits in spinosaurids. Cretac. Res. 93, 275-284, https://doi.org/10.1016/j. cretres.2018.06.013 (2018).

13. Buffetaut, E., Martill, D. M. \& Escuillié, F. Pterosaurs as part of a spinosaur diet. Nature 430, 33 (2004).

14. Amiot, R. et al. Oxygen isotope composition of continental vertebrate apatites from Mesozoic formations of Thailand; environmental and ecological significance. Geol. Soc. Spec. Publ. Special Publication 315(1), 271-283, https://doi.org/10.1144/SP315.19 (2009).

15. Amiot, R. et al. Oxygen and carbon isotope compositions of middle Cretaceous vertebrates from North Africa and Brazil: Ecological and environmental significance. Palaeogeogr. Palaeoclimatol. Palaeoecol. 297, 439-451, https://doi.org/10.1016/j.palaeo.2010.08.027 (2010).

16. Evers, S. W., Rauhut, O. W. M., Milner, A. C., McFeeters, B. \& Allain, R. A reappraisal of the morphology and systematic position of the theropod dinosaur Sigilmassasaurus from the "middle" Cretaceous of Morocco. PeerJ 3, e1323, https://doi.org/10.7717/ peerj.1323 (2015).

17. Ibrahim, N. et al. Tail-propelled aquatic locomotion in a theropod dinosaur. Nature 581, 67-70 (2020).

18. Martill, D. M., Cruickshank, A. R. I. \& Frey, E. A new crested maniraptoran dinosaur from the Santana Formation (Lower Cretaceous) of Brazil. J. Geol. Soc. 153, 5-8 (1996).

19. Sues, H.-D., Frey, E., Martill, D. M. \& Scott, D. M. Irritator challengeri, a spinosaurid (Dinosauria: Theropoda) from the Lower Cretaceous of Brazil. J. Vertebr. Paleontol. 22, 535-547; https://doi.org/10.1671/0272-4634(2002)022[0535:ICASDT]2.0.CO;2 (2002).

20. Rogers, S. W. Exploring dinosaur neuropaleobiology: viewpoint computed tomography scanning and analysis of an Allosaurus fragilis endocast. Neuron 21, 673-679 (1998).

21. Rogers, S. W. Allosaurus, crocodiles, and birds: evolutionary clues from spiral computed tomography of an endocast. Anat. Rec. 257, 162-173 (1999).

22. Franzosa, J. \& Rowe, T. Cranial endocast of the Cretaceous theropod dinosaur Acrocanthosaurus atokensis. J. Vertebr. Paleontol. 25, 859-864 (2005).

23. Sampson, S. D. \& Witmer, L. M. Craniofacial anatomy of Majungasaurus crenatissimus (Theropoda: Abelisauridae) from the Late Cretaceous of Madagascar. J. Vertebr. Paleontol. 27, 32-104; https://doi.org/10.1671/0272-4634(2007)27[32:CAOMCT]2.0.CO;2 (2007).

24. Witmer, L. M. \& Ridgely, R. C. New insights into the brain, braincase, and ear region of tyrannosaurs (Dinosauria, Theropoda), with implications for sensory organization and behavior. Anat. Rec. (Hoboken, N.J.: 2007) 292(9), 1266-1296, https://doi.org/10.1002/ ar.20983 (2009).

25. Paulina-Carabajal, A. \& Canale, J. I. Cranial endocast of the carcharodontosaurid theropod Giganotosaurus carolinii Coria \& Salgado, 1995. N. Jb. Geol. Paläont. Abh. 258(2), 249-256 (2010).

26. Balanoff, A. M., Bever, G. S. \& Norell, M. A. Reconsidering the avian nature of the oviraptorosaur brain (Dinosauria: Theropoda). PLoS One 9(12), e113559, https://doi.org/10.1371/journal.pone.0113559 (2014).

27. Hopson, J. A. Paleoneurology in Biology of the Reptilia (ed. Gans, C.) 39-146 (Academic Press, 1979).

28. Rogers, S.W. Reconstructing the behaviors of extinct species: an excursion into comparative paleoneurology. Am. J. Med. Genet. 134A, 349-356; 0.1002/ajmg.a.30538 (2005).

29. Witmer, L. M., Ridgely, R. C., Dufeau, D. L. \& Semones, M. C. Using CT to peer into the past: 3D visualization of the brain and ear regions of birds, crocodiles, and nonavian dinosaurs in Anatomical imaging: towards a new morphology (ed. Endo, H. \& Frey, R.) 67-87 (Springer, 2008).

30. Evers, S. W. et al. Neurovascular anatomy of the protostegid turtle Rhinochelys pulchriceps and comparisons of membranous and endosseous labyrinth shape in an extant turtle. Zool. J. Linnean. Soc. 187, 800-828, https://doi.org/10.1093/zoolinnean/zlz063 (2019).

31. Jerison, H. J. Evolution of the brain and intelligence (Academic Press, 1973).

32. Iwaniuk, A. N. \& Nelson, J. E. Can endocranial volume be used as an estimate of brain size in birds? Can. J. Zool. 80, 16-23, https:// doi.org/10.1139/Z01-204 (2002).

33. Witmer, L. M., Chatterjee, S., Franzosa, J. \& Rowe, T. Neuroanatomy of flying reptiles and implications for flight, posture and behaviour. Nature 425, 950-953, https://doi.org/10.1038/nature02048 (2003).

34. Rowe, T. B., Macrini, T. E. \& Luo, Z.-X. Fossil evidence on the origin of the mammalian brain. Science 332, 955-957, https://doi. org/10.1126/science.1203117 (2011).

35. Walsh, S. A. et al. Avian cerebellar floccular fossa size is not a proxy for flying ability in birds. PLoS One 8(6), e67176, https://doi. org/10.1371/journal.pone.0067176 (2013).

36. Balanoff, A. M. et al. Best practices for digitally constructing endocranial casts: examples from birds and their dinosaurian relatives. J. Anat. 229 (2), https://doi.org/10.1111/joa.12378 (2015).

37. Balanoff, A. M. \& Bever, G. S. The role of endocasts in the study of brain evolution in Evolution of nervous systems (ed. Kaas, J.) 223-241; https://doi.org/10.1016/B978-0-12-804042-3.00023-3 (2017). 
38. Sanders, R. K. \& Smith, D. K. The endocranium of the theropod dinosaur Ceratosaurus studied with computed tomography. Acta Palaeontol. Pol. 50(3), 601-616 (2005).

39. Saveliev, S. V. \& Alifanov, V. R. A new study of the brain of the predatory dinosaur Tarbosaurus bataar (Theropoda, Tyrannosauridae). Paleontol. J. 41(3), 281-289 (2007).

40. Lautenschlager, S., Rayfield, E. J., Altangerel, P., Zanno, L. E. \& Witmer, L. M. The endocranial anatomy of therizinosauria and its implications for sensory and cognitive function. PLoS One 7, e52289, https://doi.org/10.1371/journal.pone.0052289 (2012).

41. Schade, M., Rauhut, O. W. M. \& Evers, S. W. Project: Schade et al. Irritator challengeri SMNS 58022 neuroanatomy. MorphoSource, available at https://www.morphosource.org/Detail/ProjectDetail/Show/project_id/951 (2020).

42. Benson, R. B. J., Starmer-Jones, E., Close, R. A. \& Walsh, S. A. Comparative analysis of vestibular ecomorphology in birds. J. Anat. 231, 990-1018, https://doi.org/10.1111/joa.12726 (2017).

43. Witmer, L. M. \& Ridgely, R. C. The Cleveland tyrannosaur skull (Nanotyrannus or Tyrannosaurus): new findings based on CT scanning, with special reference to the braincase. Kirtlandia 57, 61-81 (2010).

44. Paulina-Carabajal, A. \& Filippi, L. Neuroanatomy of the abelisaurid theropod Viavenator: The most complete reconstruction of a cranial endocast and inner ear for a South American representative of the clade. Cretac. Res. 83, 84-94, https://doi.org/10.1016/j. cretres.2017.06.013 (2018).

45. Walsh, S. A., Barrett, P. M., Milner, A. C., Manley, G. \& Witmer, L. M. Inner ear anatomy is a proxy for deducing auditory capability and behaviour in reptiles and birds. Proc. R. Soc. B 276, 1355-1360 (2009).

46. Witmer, L. M. \& Ridgley, R. C. The paranasal air sinuses of predatory and armored dinosaurs (Archosauria: Theropoda and Ankylosauria) and their contribution to cephalic structure. Anat. Rec. 291, 1362-1388 (2008).

47. Sobral, G. \& Müller, J. Archosaurs and their kin: the ruling reptiles in Evolution of the vertebrate ear (ed. Clack, J. A., Fay, R. R. \& Popper, A. N.) 285-326 (Springer, 2016)

48. Madsen, J. H. J. Allosaurus fragilis: a revised osteology. Utah Geological and Mineralogical Survey Bulletin 109, 3-163 (1976)

49. Chure, D. J. \& Loewen, M. A. Cranial anatomy of Allosaurus jimmadseni, a new species from the lower part of the Morrison Formation (Upper Jurassic) of Western North America. PeerJ 8, e7803, https://doi.org/10.7717/peerj.7803 (2020).

50. Spoor, F. \& Zonneveld, F. Comparative review of the human bony labyrinth. Yearbook of Physical Anthropology 41, 211-251 (1998).

51. Spoor, F. et al. The primate semicircular canal system and locomotion. PNAS. 104, 10808-10812 (2007).

52. Cox, P. G. \& Jeffery, N. Semicircular canals and agility: the influence of size and shape measures. J. Anat. 216, 37-47, https://doi. org/10.1111/j.1469-7580.2009.01172.x (2010).

53. Pfaff, C., Martin, T. \& Ruf, I. Bony labyrinth morphometry indicates locomotor adaptations in the squirrel-related clade (Rodentia, Mammalia). Proc. R. Soc. B. 282, 20150744, https://doi.org/10.1098/rspb.2015.0744 (2015).

54. Pfaff, C., Czernym, S., Nagel, D. \& Kriwet, J. Functional morphological adaptations of the bony labyrinth in marsupials (Mammalia, Theria). J. Morphol. 278, 742-749, https://doi.org/10.1002/jmor.20669 (2017).

55. Georgi, J. A. \& Sipla, J. S. Comparative and functional anatomy of balance in aquatic reptiles and birds in Sensory evolution on the threshold: adaptations in secondarily aquatic vertebrates (ed. Thewissen, J. G. M. \& Nummela, S.) 233-256 (University of California Press, 2008).

56. Neenan, J. M. et al. Evolution of the sauropterygian labyrinth with increasingly pelagic lifestyles. Curr. Biol. CB 27, 3852-3858.e3, https://doi.org/10.1016/j.cub.2017.10.069 (2017).

57. Schwab, J. A. et al. Inner ear sensory system changes as extinct crocodylomorphs transitioned from land to water. PNAS, 202002146 (2020).

58. Dudgeon, T. W., Maddin, H. C., Evans, D. C. \& Mallon, J. C. The internal cranial anatomy of Champsosaurus (Choristodera: Champsosauridae): Implications for neurosensory function. Sci. Rep. 10, 7122 (2020).

59. Spoor, F. \& Thewissen, J. G. M. Comparative and functional anatomy of balance in aquatic mammals in Sensory evolution on the threshold, adaptations in secondarily aquatic vertebrates. (ed. Thewissen, J. G. M. \& Nummela, S.) 65-81 (University of California Press, 2008).

60. Georgi, J. A., Sipla, J. S. \& Forster, C. A. Turning semicircular canal function on its head: dinosaurs and a novel vestibular analysis. Plos One 8(3), e58517, https://doi.org/10.1371/journal.pone.0058517 (2013).

61. Neenan, J. M., Chapelle, K. E. J., Fernandez, V. \& Choiniere, J. N. Ontogeny of the Massospondylus labyrinth: implications for locomotory shifts in a basal sauropodomorph dinosaur. Palaeontology 62, 255-265, https://doi.org/10.1111/pala.12400 (2019).

62. Chapelle, K. E. J. et al. A quantitative method for inferring locomotory shifts in amniotes during ontogeny, its application to dinosaurs and its bearing on the evolution of posture. Palaeontology 1-14; https://doi.org/10.1111/pala.12451 (2019).

63. De Zeeuw, C. I. \& Koekkoek, S. K. E. Signal processing in the C2 module of the flocculus and its role in head movement control. Prog. Brain Res. 114, 299-321 (1997).

64. Cerroni, M. A. \& Paulina-Carabajal, A. Novel information on the endocranial morphology of the abelisaurid theropod Carnotaurus sastrei. C. R. Palevol. 18, 985-995, https://doi.org/10.1016/j.crpv.2019.09.005 (2019).

65. Sipla, J. S. The semicircular canals of birds and non-avian theropod dinosaurs. PhD Thesis, Stony Brook University (2007).

66. Wilson, V.J. \& Melville-Jones, G. Mammalian vestibular physiology (Springer, 1979).

67. Dujim, M. On the head posture in birds and its relation to some anatomical features. Proceedings of the Koninklijke Nederlandse Akademie Van Wetenschappen, Series C. Biological and Medical Sciences 54, 260-271 (1951).

68. Hullar, T. E. Semicircular canal geometry, afferent sensitivity, and animal behavior. Anat. Rec. 288A, 466-472, https://doi. org/10.1002/ar.a.20304 (2006).

69. Marugán-Lobón, J., Chiappe, L. M. \& Farke, A. A. The variability of inner ear orientation in saurischian dinosaurs: testing the use of semicircular canals as a reference system for comparative anatomy. Peer I 1, e124 (2013).

70. Rauhut, O. W. M. Morphology and mechanics of the jaws of spinosaurid theropods (Dinosauria): implications for predation. Ameghiana 38(4) Suplemento-Resumenes (2001).

71. George, I. D. \& Holliday, C. M. Trigeminal nerve morphology in Alligator mississippiensis and its significance for crocodyliform facial sensation and evolution. Anat. Rec. 296, 670-680, https://doi.org/10.1002/ar.22666 (2013).

72. Barker, C. T., Naish, D., Newham, E., Katsamenis, O. L. \& Dyke, G. Complex neuroanatomy in the rostrum of the Isle of Wight theropod Neovenator salerii. Sci. Rep. 7, 3749, https://doi.org/10.1038/s41598-017-03671-3 (2017).

73. Rayfield, E. J. Cranial mechanics and feeding in Tyrannosaurus rex. Proc. R. Soc. Lond. B. Biol. Sci. 271(1547), 1451-1459, https:// doi.org/10.1098/rspb.2004.2755 (2004).

74. Rayfield, E. J. Using finite-element analysis to investigate suture morphology: a case study using large carnivorous dinosaurs. Anat. Rec. A. Discov. Mol. Cell. Evol. Biol. 283(2), 349-365, https://doi.org/10.1002/ar.a.20168 (2005).

75. Rayfield, E. J. Structural performance of tetanuran theropod skulls, with emphasis on the Megalosauridae, Spinosauridae and Carcharodontosauridae. Special Papers in Palaeontology 86, 241-253 (2011) 


\section{Acknowledgements}

We thank the German Heart Centre in Munich (especially Jacqueline Jendick and Cornelia Pankalla) and Zeiss in Essingen (especially Nicole Kreuzer) for the CT-scans of the skull of Irritator. Furthermore, we are deeply grateful for the help of the Cytology and Evolutionary Biology group of the Zoological Institute and Museum, University Greifswald (especially Marie Hörnig and Steffen Harzsch) and the Freunde der Bayerischen Staatssammlung für Paläontologie und Geologie München e.V. (especially Martin Nose). Additionally, Lehre@LMU (especially Tanja Schulz-Mirbach), the chair of Paleontology and Historical Geology (especially Ingelore Hinz-Schallreuter and Stefan Meng), Gertrud Rößner, Christoph Kettler and Benjamin Englich supported this project. Susannah Maidment, Neil Gostling and Chris Barker allowed provided access to material of Baryonyx. Gabriela Sobral and Cathrin Pfaff are thanked for discussions. We thank Rainer Schoch for access to SMNS 58022 and permission to loan the specimen in order to conduct CT scans. We also thank Stephan Lautenschlager, Matt White, and an anonymous reviewer for very constructive comments that improved an earlier version of this MS, as well as Heather Smith for editorial handling of our submission.

\section{Author contributions}

M.S. and O.W.M.R. designed the project. M.S. organized the CT scans and segmented the data. S.W.E. prepared the figures. M.S., O.W.M.R. and S.W.E. interpreted the data and wrote the manuscript.

\section{Competing interests}

The authors declare no competing interests.

\section{Additional information}

Correspondence and requests for materials should be addressed to M.S.

Reprints and permissions information is available at www.nature.com/reprints.

Publisher's note Springer Nature remains neutral with regard to jurisdictional claims in published maps and institutional affiliations.

(c) (i) Open Access This article is licensed under a Creative Commons Attribution 4.0 International License, which permits use, sharing, adaptation, distribution and reproduction in any medium or format, as long as you give appropriate credit to the original author(s) and the source, provide a link to the Creative Commons license, and indicate if changes were made. The images or other third party material in this article are included in the article's Creative Commons license, unless indicated otherwise in a credit line to the material. If material is not included in the article's Creative Commons license and your intended use is not permitted by statutory regulation or exceeds the permitted use, you will need to obtain permission directly from the copyright holder. To view a copy of this license, visit http://creativecommons.org/licenses/by/4.0/.

(C) The Author(s) 2020 